\title{
Lessons learned from radiology mentors
}

\author{
Rachel M. Perez ${ }^{3} \cdot$ Yoan K. Kagoma ${ }^{1} \cdot$ Nelly Tan $^{2} \mathbb{D}$
}

Received: 30 March 2021 / Revised: 15 June 2021 / Accepted: 16 June 2021 / Published online: 10 July 2021

(C) The Author(s), under exclusive licence to Springer Science+Business Media, LLC, part of Springer Nature 2021

\begin{abstract}
As in any field, radiologists may face a number of challenges as they navigate their early careers. Because with experience comes wisdom, early-career radiologists may find helpful the advice and perspectives of mid- and late-career radiologists. The Society of Abdominal Radiology recognizes the value of this pool of knowledge and experience, prompting the establishment of the Early Career Committee. This group is designed to support early-career radiologists by sharing the experiences and insights of leaders in the field. In this series, the authors interview trailblazers Matthew S. Davenport, MD; Jonathan B. Kruskal, MD, PhD; Katherine E. Maturen, MD, MS; David B. Larson, MD, MBA; and Desiree E. Morgan, MD. This perspective explores a wide range of subjects, including personal values in medicine, the role of teleradiology, diversity of backgrounds in radiology, how to navigate workplace conflict, and lifelong learning in medicine. Beyond conveying these pearls of wisdom, the aim of this perspective is to highlight for early-career radiologists the value that mid- and late-career mentors can provide in navigating careers in medicine.
\end{abstract}

Keywords Academic success $\cdot$ Advice $\cdot$ Growth $\cdot$ Mentors $\cdot$ Perspectives $\cdot$ Values

\section{Introduction}

Radiology has always been an evolving field, but many challenges facing early-career radiologists remain the same over time. These physicians may benefit from looking to their predecessors in radiology. Sponsored by the Society of Abdominal Radiology Early Career Committee, 2 of the authors (Y.K.K. and N.T.) interviewed experienced, midand late-career radiologists who are leaders in their field. In this series, we explore subjects such as value-oriented careers, benefits and challenges surrounding teleradiology, and value of diverse backgrounds in medicine. Our goal was to share these insights and perspectives to help early-career professionals best equip themselves for success.

Nelly Tan

tan.nelly@mayo.edu

1 Department of Radiology, McMaster University, Hamilton, ON, Canada

2 Division of Abdominal Imaging, Mayo Clinic, 13400 E Shea Blvd, Scottsdale, AZ 85259, USA

3 Mayo Clinic Alix School of Medicine - Arizona Campus, Scottsdale, AZ, USA

\section{Seeking a value-oriented life and career}

As a physician, researcher, and mentor, Matthew S. Davenport, MD, an abdominal radiologist and associate chair of operations at the University of Michigan at Ann Arbor, Michigan, actively chooses to center his life and career on his values. He recommends finding a "virtue, principle, or ideal to guide you, rather than something transactional like finances, egoism, or a title," which he cautions will not lead to happiness. Research on the relationship between income and happiness consistently indicates diminishing satisfaction from wealth accumulation $[1,2]$. Further supporting Dr Davenport's advice, studies show that extrinsic goals, such as material possessions, are associated with greater life dissatisfaction [3] while intrinsic goals, such as self-acceptance, affiliation, and feelings of community, are associated with greater well-being [4]. He advises early-career professionals to distill a list of their top 5 values and rely on it to avoid such distractions as salary and vacation days when facing career crossroads. One value, a positive workplace environment, has led Dr Davenport to 2 of his great passions: career mentorship and quality of care. He believes that a values list can do the same for others.

Dr Davenport's emphasis on mentorship is especially important in the field of radiology, where many residency 
programs lack formal mentorship programs. One study surveying integrated interventional radiology residency program directors showed that only 13 of 23 participating programs had formal mentorship and even fewer had departmental support [5]. Addressing the barriers to implementing these programs-such as financial cost and lack of time-is necessary for the development of current and future radiologists.

\section{Balance between "Old Power" and "New Power"}

From his start in medicine as a basic science laboratory intern in South Africa to his current role as chair of the Department of Radiology at Beth Israel Deaconess Medical Center in Boston, Massachusetts, Jonathan B. Kruskal, MD, $\mathrm{PhD}$, an abdominal radiologist, and the former president of the Society of Abdominal Radiology, has a wealth of experience working with people of different backgrounds. He believes that one of the greatest challenges facing the next generation of radiologists is the tug of war between "old power" and "new power." Dr Kruskal describes old power as hierarchical thinkers, whereas new power insists on flat hierarchies and better work-life integration. He clarifies that this is not simply a generational issue; there certainly are latecareer new power thinkers and early-career old power thinkers. Differences of opinion arise when facing such questions as, "What is an acceptable number of studies to read?" and "Where does one do the work of a radiologist?" Dr Kruskal staunchly believes that both schools of thought have value and are necessary for success. Recognizing this distinction may help identify and address each group's distinct needs and goals. For example, a recent study showed that earlycareer interventional radiologists feel that they have different needs than their senior counterparts, especially for mentorship, networking, and identification of the unique barriers facing early-career physicians [6].

With the coronavirus disease 2019 (COVID-19) pandemic, a new style of crisis-specific thinking and leadership was embraced: meta-leadership. Meta-leadership is a holistic framework, inclusive of emotional intelligence, situational awareness, and multidimensional connections. Dr Kruskal and other radiology chairs provided lessons learned in the article, "Enabling Your Radiology Business to Thrive: Strategic Lessons Learned During the Initial and Subsequent Surges of Covid-19 Pandemic" [7]. Kruskal and colleagues agreed that those who successfully contemplated the "new imaging world" were best prepared for supporting and sustaining predominantly virtual communities while protecting the safety of staff and patients [7]. If not already enabled to work remotely from home, most radiology practices purchased home picture archiving and communications system workstations. With the pandemic, federal and state regulatory changes were introduced to facilitate the provision of care, which accelerated the adoption of digital health and the use of videoconferencing platforms for communication between team members, imaging sharing during tumor boards, and telehealth services for patients. Dr Kruskal adds that of utmost importance during the COVID-19 pandemic was the need to cultivate appreciation in the workplace, recognize effort and intent irrespective of the outcome, and include diverse individuals and thinkers.

\section{The value of diverse backgrounds in medicine}

Despite her nontraditional path through a liberal arts philosophy degree and private teleradiology practice, Katherine E. Maturen, MD, MS, discovered her passion for academic medicine and has "not looked back." She is an abdominal radiologist and section chief of abdominal radiology at the University of Michigan in Ann Arbor. One study indicated that the popular reasons to continue in academics include opportunities for teaching, research, working with experts, and seeing an interesting case mix [8]. By comparison, popular reasons to leave academics after training include insufficient monetary compensation, large clinical workload, academic center "politics," and lack of protected academic time [8].

Dr Maturen's diverse background ultimately adds to her dimension as a physician. For example, private practice teleradiology helped her develop efficiency and an eager work ethic, which have been advantageous in academic medicine. Considering all she has learned from her experiences, $\mathrm{Dr}$ Maturen urges early-career radiologists to stop comparing their path with that of their peers. Rather, their uniqueness adds to their breadth and makes their contribution to medicine more valuable.

In his book Range: Why Generalists Triumph in A Specialized World, David Epstein argues that range-defined as more diverse experiences-is critically important to solving today's problems, which require bridging experiences and knowledge of different backgrounds [9]. Thereby, Dr Maturen's experiences in liberal arts and private practice have lent unique perspective as she solves problems in academic and larger radiology communities.

A critical step in pursuing diversity in medicine is recognizing and addressing the barriers, such as unconscious bias. Current literature recommends tackling bias in health care at both individual and institutional levels [10]. Individually, people can review research on bias, take the validated implicit associations test, and trade stereotypes for evidence-based knowledge and personal relationships with underrepresented persons. At the institutional level, leaders 
should carefully evaluate program statistics and employment processes for evidence of bias, educate staff on microaggressions, actively seek out diverse opinions, and implement unconscious bias training.

In addition to diverse backgrounds, Dr Maturen also seeks to learn from her peers' experiences. She is involved in multiple professional organizations at the national level, including the American Board of Radiology and the American College of Radiology Appropriateness Criteria panel, where she has worked with radiologists from across the US and learned how they do things differently in their practices. Dr Maturen encourages early-career radiologists to seek perspectives from physicians of different backgrounds, not only to learn but also to better appreciate the distinctiveness of each individual's contribution to medicine.

\section{Navigating workplace conflict}

On his path to roles such as vice chair for education and clinical operations in the Department of Radiology at Stanford University in Stanford, California, David B. Larson, MD, MBA, has honed the skills necessary for successfully navigating interpersonal workplace relationships. His advice is to work to develop positive professional relationships and avoid petty workplace conflicts, which he argues harm both physician careers and patient outcomes.

In fact, communication failures are the leading cause of inadvertent patient harm, but consequences can be mitigated by effective teamwork, communication, and collaboration [11]. Dr Larson recommends Give and Take: A Revolutionary Approach to Success by Adam Grant [12], in which the author describes 3 types of individuals in the workplace: givers, takers, and matchers. Givers work to help others succeed and themselves. Takers consistently place their own needs above others'. Matchers reciprocate others' good and bad deeds. Givers generally have the most successful and rewarding careers.

Dr Larson cautions, "You need to guard your time and mental energy carefully." Hallway conversations can foster enriching collaborative relationships or reinforce negativity cycles. When discussing problems with colleagues, for example, watch for that "inflection point" in which the conversation shifts to what to do about the problem. If the conversation leads to constructive ideas for a solution, it can improve the individuals' well-being and the organization's performance. But if it leaves participants with feelings of victimhood or resentment, the conversation is demoralizing, a waste of time, and harmful to the individuals and the organization. It can be a "career killer." Dr Larson chooses to live by the advice of Atul Gawande, MD, MPH, in his book Better: A Surgeon's Notes on Performance-to avoid conversations that lead to feeling sorry for oneself [13].

Negative conversations, among many other factors, may contribute to burnout-a widespread problem in medicine, and radiology is no exception. A survey of radiology practice leaders showed that $55 \%$ believed burnout to be a very significant problem and $22 \%$ believed burnout to be a significant problem [14]. Of survey participants, $71 \%$ reported workplace factors as a source of stress. When facing these stressors, Dr Larson encourages early-career radiologists to draw on the passion that first brought them to medicine, thereby to build each other up while working together to save and improve lives.

\section{Lifelong learning in medicine}

Desiree E. Morgan, MD, is a professor and vice chair for education in the Department of Radiology at the University of Alabama in Birmingham, Alabama, and the 2020-2021 president of the Society of Abdominal Radiology. She considers herself the "picture child of lifelong learning." From reading mammography in private practice during a 4-year foray as an abdominal imager to transitioning from research into graduate medical education, she has had to adapt to multiple changing roles throughout her career. For early-career professionals facing anxiety surrounding new responsibilities, Dr Morgan provides reassurance that this is a natural reaction, which she still experiences even as one of the most senior members of her department. She urges them to approach these tasks with self-directed learning and the confidence that even when they do not know how to do something, they can learn how to do it.

Medical education research has confirmed that selfregulated learning contributes to a trainee's self-perceived competence [15]. This learning style involves personally reflecting on one's performance and actively seeking feedback from superiors [15]. Every career in medicine necessitates adaptability and a willingness to learn along the way, Dr Morgan emphasizes, so using these methods can best prepare early-career professionals for success.

\section{Conclusion}

Early-career radiologists are likely to encounter many of the challenges discussed herein. They may benefit from the advice of mid- and late-career radiologists who have faced these challenges firsthand and learned from their experiences. This interview series addresses issues ranging from internal fulfillment to external conflicts. It advises earlycareer professionals to create-and rely on-their top 5 values, seek balance rather than divisiveness, and find peace 
with their unique, personal path through medicine. Beyond conveying these pearls of wisdom, the aim of this perspective is to highlight for early-career radiologists the value that mid- and late-career mentors can provide in navigating careers in medicine.

Acknowledgements We thank the physicians interviewed for taking time to share their perspectives.

Funding Not applicable.

\section{Declarations}

Conflict of interest All authors declare that they have no conflict of interest.

Consent to participate All interviewees.

Consent for publication All interviewees.

\section{References}

1. Frey BS, Stutzer A (2002) What Can Economists Learn from Happiness Research? J Econ Lit 40 (2):402-435. doi:https://doi.org/ $10.1257 / 002205102320161320$

2. Helliwell JF (2003) How's life? Combining individual and national variables to explain subjective well-being. Econ Model 20 (2):331-360. doi:https://doi.org/10.1016/S0264-9993(02) 00057-3

3. Sirgy MJ (1998) Materialism and Quality of Life. Soc Indic Res 43 (3):227-260. doi:https://doi.org/10.1023/A:1006820429653

4. Kasser T, Ryan RM (2001) Be careful what you wish for: optimal functioning and the relative attainment of intrinsic and extrinsic goals In: Schmuck P, Sheldon KM (eds) Life goals and wellbeing: towards a positive psychology of human striving. Hogrefe \& Huber Publishers, Seattle, pp 116-131

5. Hoffmann JC, Minkin J, Karimi V, Warhadpande S, Khaja MS, Bercu ZL, Majdalany B, Kaufman CS, Martin CE, 3rd (2020) Assessing the Status of Mentorship Programs in Interventional Radiology Residency Training: Results of a 2018 Survey. Curr
Probl Diagn Radiol 49 (3):154-156. doi:https://doi.org/10.1067/j. cpradiol.2020.03.002

6. Khaja MS, Contrella BN, Wilkins LR, Pyne R, Majdalany BS, Rajebi R, Saad WE, Findeiss L (2021) Issues Most Pressing to Early-Career Interventional Radiologists: Results of a Descriptive Survey. Acad Radiol. doi:https://doi.org/10.1016/j.acra.2021.02. 023

7. Kruskal JB, Rosen MP, Hara AK, Canon C, Wald C (2021) Enabling Your Radiology Business to Thrive Strategic Lessons Learned During the Initial and Subsequent Surges of the Covid19 Pandemic. Acad Radiol 28 (3):393-401. doi:https://doi.org/10. 1016/j.acra.2021.01.005

8. Kelly AM, Cronin P, Dunnick NR (2007) Junior faculty satisfaction in a large academic radiology department. Acad Radiol 14 (4):445-454. doi:https://doi.org/10.1016/j.acra.2007.01.017

9. Epstein D (2019) Range: Why Generalists Triumph in a Specialized World. New York: Riverhead Books

10. Allen BJ, Garg K (2016) Diversity Matters in Academic Radiology: Acknowledging and Addressing Unconscious Bias. J Am Coll Radiol 13 (12 Pt A):1426-1432. https://doi.org/10.1016/j. jacr.2016.08.016

11. Leonard M, Graham S, Bonacum D (2004) The human factor: the critical importance of effective teamwork and communication in providing safe care. Qual Saf Health Care 13 Suppl 1:i85-90. doi:https://doi.org/10.1136/qhc.13.suppl_1.i85

12. Grant AM (2013) Give and take : a revolutionary approach to success. Viking, New York, N.Y.

13. Gawande A (2008) Better: A Surgeon's Notes on Performance. Henry Holt and Company, New York

14. Parikh JR, Wolfman D, Bender CE, Arleo E (2020) Radiologist Burnout According to Surveyed Radiology Practice Leaders. J Am Coll Radiol 17 (1 Pt A):78-81. https://doi.org/10.1016/j.jacr. 2019.07.008

15. Sagasser MH, Kramer AWM, Fluit C, van Weel C, van der Vleuten CPM (2017) Self-entrustment: how trainees' self-regulated learning supports participation in the workplace. Adv Health Sci Educ Theory Pract 22 (4):931-949. doi:https://doi.org/10.1007/ s10459-016-9723-4

Publisher's Note Springer Nature remains neutral with regard to jurisdictional claims in published maps and institutional affiliations. 